\title{
Characterization of a "Smart" Hybrid Varnish Electrospun Nylon Benzotriazole Copper Corrosion Protection Coating
}

\author{
C. Menchaca, ${ }^{1}$ I. Castañeda, ${ }^{1}$ A. Soto-Quintero, ${ }^{1}$ R. Guardián, ${ }^{1}$ \\ R. Cruz, ${ }^{1}$ M. A. García-Sánchez, ${ }^{2}$ and J. Uruchurtu ${ }^{1}$ \\ ${ }^{1}$ Centro de Investigación en Ingeniería y Ciencias Aplicadas (CIICAp), Universidad Autónoma del Estado de Morelos (UAEM), \\ Avenida Universidad No. 1001, Col. Chamilpa, 62209 Cuernavaca, MOR, Mexico \\ ${ }^{2}$ Depatrmento de Química, Universidad Autónoma Metropolitana-Iztapalapa, Avenida San Rafael Atlixco 186, Col. Vicentina, \\ 09340 Iztapalapa, DF, Mexico
}

Correspondence should be addressed to J. Uruchurtu, juch25@uaem.mx

Received 10 August 2012; Revised 23 October 2012; Accepted 24 October 2012

Academic Editor: Flavio Deflorian

Copyright (๑) 2012 C. Menchaca et al. This is an open access article distributed under the Creative Commons Attribution License, which permits unrestricted use, distribution, and reproduction in any medium, provided the original work is properly cited.

\begin{abstract}
This work presents the electrochemical evaluation of a proposed copper corrosion protection hybrid coating acting as a smart corrosion protection system. This consists of an alkyd varnish, painted over electrospun nylon fibers acting as a secondary diffusion barrier and also as a benzotriazole (BTAH) inhibitor nanocontainer. Submicron diameter electrospun nylon 6-6 fiber nanocontainers were prepared from a polymeric solution containing BTAH at different concentrations, and Cu samples were coated with the electrospun fibers and painted over with an alkyd varnish by the drop method. Functional groups in fibers were determined through FTIR spectroscopy. Optical and SEM microscopies were used to characterize the nanocontainer fibers. Samples were evaluated using electrochemical impedance and noise, during six weeks of immersion, in a chloride-ammonium sulfate solution. Excellent response was obtained for the smart inhibitor coating system. For long periods of immersion good corrosion protection performance was observed. The results presented demonstrate the good barrier properties of the hybrid coating, obstructing the diffusion of aggressive species, through the electrospun structure. Furthermore the nanocontainer functionality to store and liberate the corrosion inhibitor, only when it is needed, was also proved.
\end{abstract}

\section{Introduction}

As far as metallic monuments, statues, and works of art are concerned, accounts for the vast majority of existing and cultural heritage objects. Copper and its alloys play an important role as a base metallic material used by artists and architects. A vast majority of existing and cultural heritage objects are metallic monuments, statues, and works of art. Corrosion processes is a complex phenomenon involving corrosion products or oxide film formation on copper and alloys. These products are formed by a number of brittle oxide and hydroxide surface layers, in many cases of different colors and textures, some of calcareous origin including silicates, and all of them formed over the copper oxidation patina (typically cuprite) [1-5].

Copper, commonly used in structures and sculptures, is usually covered with layers of corrosion products providing its aesthetic value and, at the same time, protecting the metallic substrate. Due to the increase in atmospheric pollution, these layers commonly dissolve when exposed to the urban environment.

Polymeric materials efficiency as corrosion protection coatings for metals increases when polymeric ligands are modified using corrosion inhibitors. Nanocontainers with storage properties, liberating inhibitors in a controlled way, can be used to manufacture a new family of hybrid coatings that respond to changes within the coating environment or its integrity. Liberation of encapsulated inhibitors within nanocontainers is activated by the corrosion process itself, preventing spontaneous leaking out of the inhibitor from the coating. With this restriction, it is possible to reach the double goal of corrosion protection by a barrier and inhibitor mechanism of metallic elements. 


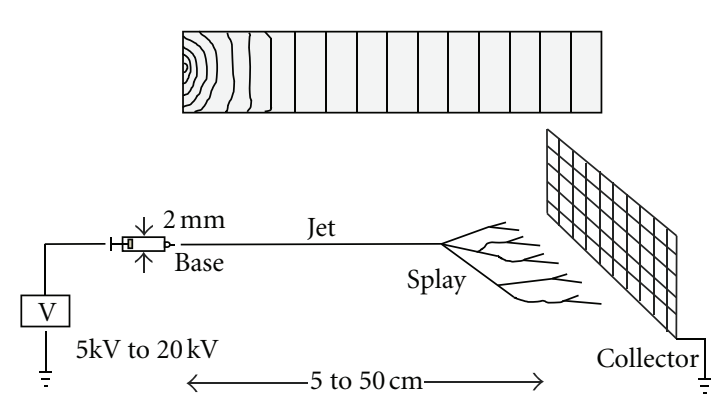

(a)

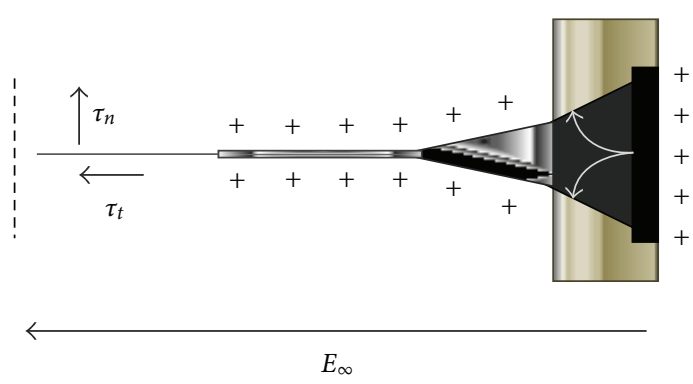

(b)

Figure 1: (a) Electrospinning system. (b) Taylor's cone.

Electrospinning is a recognized technique to create polymer fibers with diameter ranging from 40 to 2000 nanometers. Fibers can be electrospun direct from solution or from the fused material state, controlling the diameter size through adjustment of the surface tension, solution concentration, conductivity, and so forth [5-8]. Electrospinning occurs when the electric force of the solution surface overcomes the surface tension and triggers an electric spark provoking the solution to be expelled from the containing device (syringe) and the jet flow impacts, deposits, and is collected in a metal screen. When the expelled material dries out or solidifies, it forms an electric charged fiber, and this could be directed or speeded up by electric forces [1-8]. In other words, a polymer solution in a syringe is charged to a high electrical potential. As the jet stretches and dries, radial electrical forces cause it to splash repeatedly. The dried, solidified fibers are collected on an electrically conducting screen (Figure 1).

The improvements in the electrospinning technique allowed production of liquid crystals or other tailored systems and even thinner fibers [9]. The thermodynamic compatibility between polymers and corrosion inhibitors allows their combination as an integral material system, creating quasicompatible compounds. This is the direction in which polymer-inhibitor materials science is progressing [10].

Inhibitors are compounds capable of diminishing metal corrosion, even at very low concentrations in aggressive media. They change the electrochemical reaction kinetics producing corrosion, and the rate is significantly slowed down [11-16]. Corrosion processes include, in most cases, water molecules, and inhibitors are used in aqueous systems and in atmospheric corrosion protection. Nowadays, corrosion inhibitors do exist such as chromates, nitrites, benzotriazole, and other organic and inorganic compounds. Benzotriazole (BTAH) is an organic compound of low molecular weight with metallic corrosion inhibitor properties, for copper in particular.

The aim of this work is to produce a corrosion protection hybrid coating containing polymer varnish and nanofibers acting as an inhibitor nanocontainer and the whole as a smart system. This was characterized throughout instrumental analysis and its electrochemical performance evaluated.

\section{Experimental Procedure}

2.1. Coating Preparation. Coating preparation was made from the benzotriazole (BTAH) inhibitor and nylon 66 mixture. Electrospinning of nylon 6-6 and its different mixtures with corrosion inhibitor was prepared under environmental room temperature $\left(25^{\circ} \mathrm{C}\right)$. To decide the best concentration, nylon 6-6-BTAH fibers were electrospun at different BTAH by weight concentrations: $10 \% \mathrm{wt}$ (NyBTAH 10\%), 20\% (Ny-BTAH 20\%), and 30\% wt (Ny-BTAH $30 \%$ ) concentrations. To each mixture formic acid was added. All these were mixed and left under gentle agitation for approximately $15 \mathrm{~h}$.

The electrospinning system (Figure 1(a)) consists of a controlled power source (Glassman High Voltage, Inc.) providing a high voltage to create a high electrostatic field, an injector or perfusion pump (SryngePump.com, Model NE-300, Volts/Hz 11 VDC, Ampere 0.75) where a syringe is connected, generating pressure, and then flows through it. When the effects of polarization and electric charge as a consequence of the electric field effect are present, a jet solution is triggered over a conducting screen or plate electrically downearthed (in this case commercial copper). During the jet formation, the solvent in the hydrodynamic flow gradually evaporates and the fluid discharges are induced through the separation distance of the electrodes (tip and collector) breaking up the surface tension across the electric field forming a tangential $\left(\tau_{t}\right)$ and a normal $\left(\tau_{n}\right)$ components, forming Taylor's cone (see Figure 1(b)).

In this work, electrospinning was carried out using a power source and a dosage syringe, at $12 \mathrm{kV}$ voltage and a tipcollector distance of 6.5 or $12 \mathrm{~cm}$ (Figure 1(a)). Beyond that, nylon 6-6 fibers were obtained without BTAH to compare the effect of the inhibitor present in the fibers. The flow rates used to obtain the fibers were 0.2 or $0.4 \mathrm{~mL} / \mathrm{h}$.

2.2. Electrode Preparation. Test samples were cut from a copper rod, into $5 \mathrm{~cm}$ length cylinders and $1 \mathrm{~cm}$ diameter. Electrical connection was provided, soldering a covered copper wire to one face of the $\mathrm{Cu}$ electrode, encapsulating with epoxy resin, and drying it at ambient temperature. Afterwards the exposed area was abraded with 80,120 , and 
200 emery carbide paper, providing a clean surface with certain roughness to allow a suitable area for good coating bonding. The electrode surface was degreased and cleaned with methanol and dried under an air stream and kept in a desiccator for further preparation or testing.

After copper electrodes were prepared, these were accommodated over the electrospinning system screen to perform the coating. For this purpose, nylon 6-6 and BTAH inhibitor at different percentage mixtures were electrospun to evaluate the coating corrosion protection degree as a function of BTAH concentration. Fibers containing 10, 20, and 30\% BTAH were electrospun, at different flow speed and tipcollector distances to obtain the best preparation conditions and optimal coating. This was formed by a homogeneous membrane in the form of a net with no fiber agglomerates [15], providing a tortuous path for diffusion of aggressive species to occur.

After deciding the best conditions, which were $12 \mathrm{kV}$, $12 \mathrm{~cm}$ from tip to collector, and $0.2 \mathrm{~mL} / \mathrm{h}$ flow rate, electrodes were prepared for electrochemical testing, electrospinning them with nylon 6-6 and 20\% BTAH fibers. Afterwards, an alkyd varnish was painted over the nylon inhibitor coating, drying at ambient temperature for 24 hours.

\subsection{Characterization}

2.3.1. Optical Microscopy. Electrospun fibers were characterized using different microscopy techniques. Electrospun fiber samples preparation (nylon "only" and nylon-BTAH) was done collecting them over pieces of porous silica during 2 seconds to analyze fiber distribution, with the help of an OLYMPUS GX71 optical microscope.

2.3.2. Scanning Electron Microscopy (SEM). For SEM analysis, fiber samples were collected in a similar way as previously but during $90 \mathrm{~min}$, to obtain the film width that is going to be used as a metal electrode coating, for electrochemical measurements. Fibers were vacuum sputtered and covered with Au-Pd to provide conductivity and analyzed using SEM Model LEO operating at $6 \mathrm{kV}$, at 1,2 , and $10 \mathrm{kX}$ resolution.

2.3.3. Infrared Spectroscopy. FT-IR spectra were registered in a spectrophotometer Model Bruker Vector 22, using OPUS 5.5 software, in the wave number range $500-4000 \mathrm{~cm}^{-1}$, using the ATR accessory.

2.4. Electrochemical Measurements. Electrochemical measurements, namely, corrosion potential, noise, and impedance (EIS) as a function of time of immersion in a $26.5 \mathrm{~g}$ sodium chloride and 3.89 ammonium sulfate per liter solution, were performed using a Gill ACM electrochemical instrument. Electrochemical tests were programmed sequentially as, corrosion potential, followed by noise and impedance measurements. Duplicate measurements were obtained, and an average value was reported.

The electrochemical free corrosion potential of the coated copper working electrode (Ecorr) was measured against a saturated calomel reference electrode (SCE).

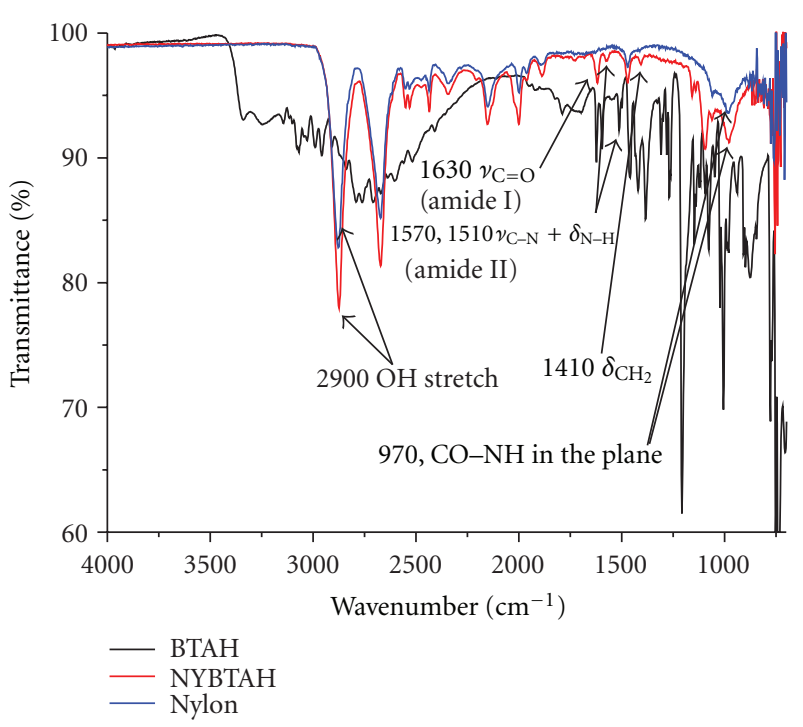

Figure 2: FT-IR of BTAH, nylon 6-6, and Ny-BTAH 20\% coating fibers spectra.

Electrochemical noise measurements (EN) in both current and potential were recorded using two "identical" working electrodes and a reference electrode (SCE). This was made recording simultaneously: the potential and current fluctuations at a $0.5 \mathrm{~s}$ sampling rate and gathering 2048 points. A fully automated zero resistance ammeter (ZRA) from ACM instruments was used in this case. Removal of the DC trend from the raw noise data was the first step in the noise analysis when needed. To accomplish this, a least square fitting method was used. Finally, the noise resistance, $\mathrm{Rn}$, was then calculated as the ratio of the potential noise standard deviation over the current noise standard deviation $(\mathrm{Rn}=\sigma v / \sigma i)[18,19]$.

EIS measurements were done at the free corrosion potential, in the frequency interval 10000 to $0.05 \mathrm{~Hz}$, with $\pm 20 \mathrm{mV}$ amplitude using beside the working electrode and the SCE a graphite auxiliary electrode. Fifty points were obtained, and 7 decades of frequency were covered during measurements $[16,18,19]$.

\section{Results}

Once coating films were elaborated, they were characterized by infrared spectroscopy FT-IR, where spectra nylon 6-6, solid BTAH, and Ny-BTAH 20\% electrospun fibers are presented in Figure 2. Absorption peaks for BTAH inhibitor and for nylon 6-6 were observed. The third spectrum corresponds to Ny-BTAH $20 \%$, presenting peaks corresponding to the ones observed in the other spectra, indicative of the merging of nylon and BTAH in the film formed.

Figures 3(a) and 3(b) present micrographs obtained with the optical microscope showing general and detailed views of the nylon 6-6 electro-spun and collected over a piece of porous silica, at $12 \mathrm{kV}, 12 \mathrm{~cm}$ distance, and $0.2 \mathrm{~mL} / \mathrm{h}$. A homogeneous distribution of fibers without agglomerations 


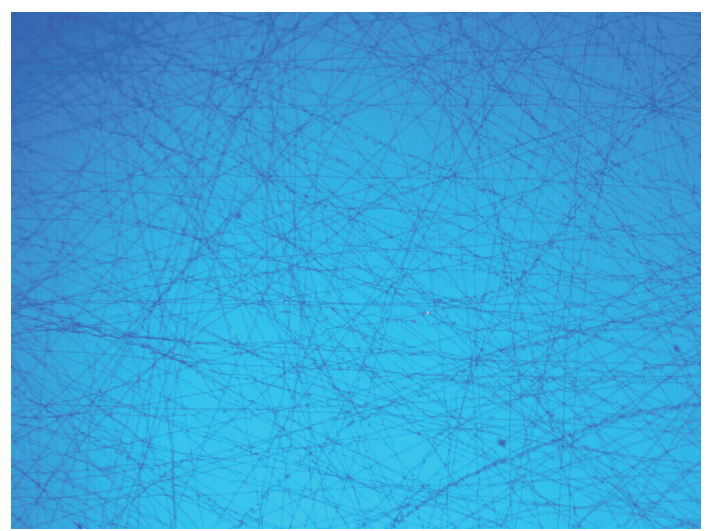

(a) $0.2 \mathrm{~mL} / \mathrm{h} 10 \mathrm{X}$

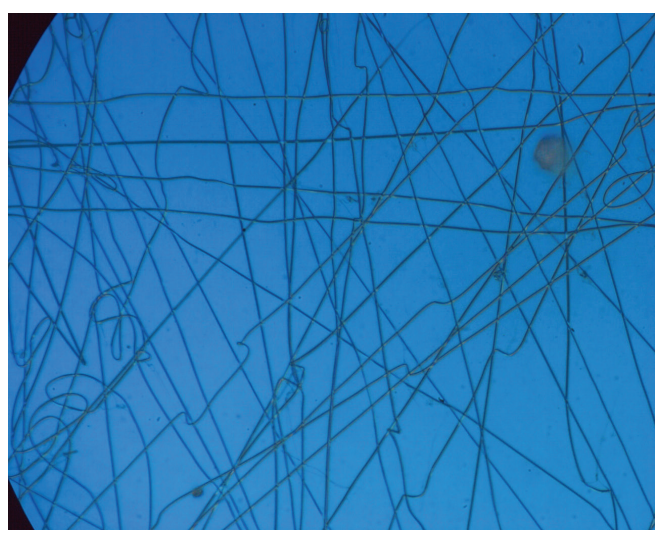

(b) $0.2 \mathrm{~mL} / \mathrm{h} 100 \mathrm{X}$

Figure 3: Optical microscope micrographs of electrospun nylon fibers.

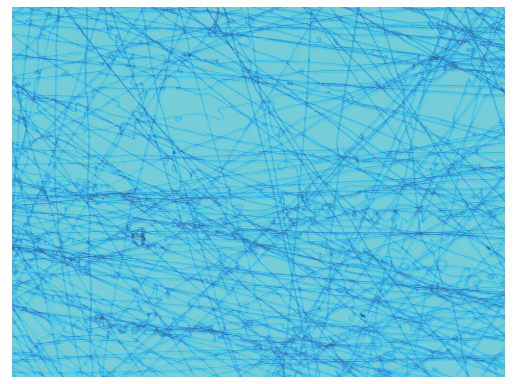

(a) Ny-BTAH $10 \%$

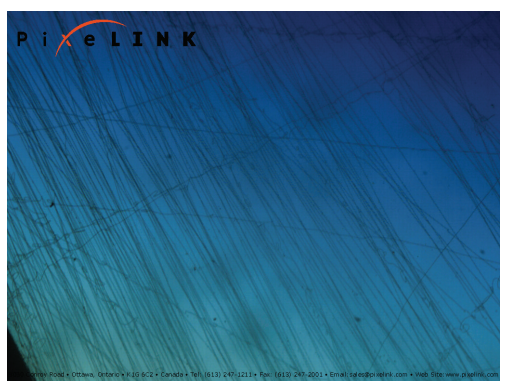

(b) Ny-BTAH $20 \%$

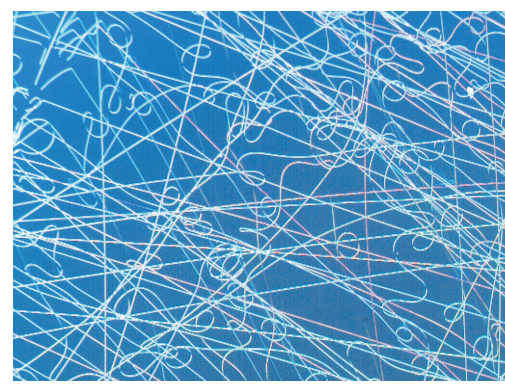

(c) Ny-BTAH $30 \%$

FIgURE 4: Optical microscope micrographs of electrospun Ny-BTAH at $12 \mathrm{kV}, 0.2 \mathrm{~mL} / \mathrm{h}$, and $12 \mathrm{~cm}$, at $10 \mathrm{X}$ magnification, for different concentrations.

can be appreciated, indicating adequate electrospinning conditions.

In the same way Figure 4 presents micrographs showing nylon 6-6 fibers-benzotriazole with (a) $10 \%$, (b) $20 \%$, and (c) 30\% BTAH wt. Homogeneous distribution forming a network without preferential orientation can be observed (Figure 4(a)) for Ny-BTAH 10\%. Fibers containing 20\% wt BTAH (Figure 4(b)), besides presenting a homogeneous distribution, show an ordered preferential orientation. Finally, Figure 4(c) presents the homogeneous distribution of fibers containing $30 \%$ wt BTAH, but forming a curly network.

For a detailed nylon 6-6 fiber characterization with BTAH at different concentrations, SEM analysis was used to produce high resolution images and therefore to determine some characteristic features. Figure 5 presents the micrographs obtained for nylon 6-6 fibers containing BTAH in different weight percentage. For fibers with $10 \%$ wt BTAH obtained at a $0.2 \mathrm{~mL} / \mathrm{h}$ flow rate and collected at $12 \mathrm{~cm}$ distance, the diameters thickness range is between 384 and $406 \mathrm{~nm}$ (Figure 5(a)). For the 20\% concentration (Figure 5(b)) varying from 318 and $328 \mathrm{~nm}$ and for the $30 \%$ concentration (Figure 5(c)), the range is $667-792 \mathrm{~nm}$. The thinner fibers were found in the BTAH $20 \%$ by weight concentration.

Figure 6(a) presents the range of fiber diameter as a function of BTAH concentration by weight as well as the coating without inhibitor. These results were obtained using the best electrospinning conditions encountered, that is, $0.2 \mathrm{~mL} / \mathrm{h}$ with a $12 \mathrm{~cm}$ tip-collector distance, using a $12 \mathrm{kV}$ power voltage, for all cases [15]. Accordingly, it was found in general that thickness increases as a function of BTAH \% weight, as compared to the sample without inhibitor. Relating all the previous results presented, the best conditions could be established for the polymeric coating-inhibitor manufacture. But for the 20\% inhibitor range, fibers are thinner diameters lower and more homogeneous than for the other two inhibitor concentration conditions. A possible explanation could be that, for the specific experimental conditions, the $20 \%$ BTAH is the critical concentration where nylon fibers are covered, with the solvent being evaporated completely while the electrospun mix solution impacts the collector. At $10 \%$ BTAH the mixture lacks BTAH and nylon behavior predominates, while at $30 \% \mathrm{BTAH}$ too much is present in the mixture and BTAH liquid drops are formed avoiding proper electrospun fiber formation (see Figures 4 and 5).

Coating adhesion tests were performed according to standard ASTM D 3359-97, before and after immersion. Figure 6(b) presents the Ny-BTAH 20\% sample condition, showing the degree of adhesion in the artificially damaged scribed area, presenting certain disbonding condition in the damaged area. 


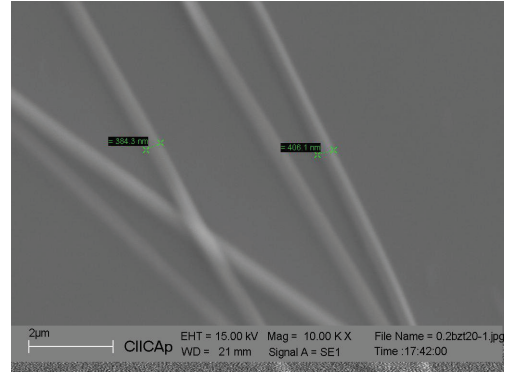

(a) $384-406 \mathrm{~nm}$

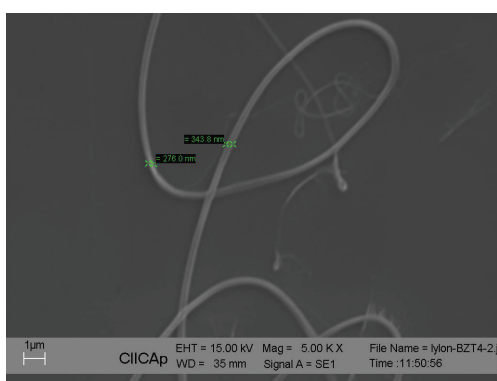

(b) 318 and $328 \mathrm{~nm}$

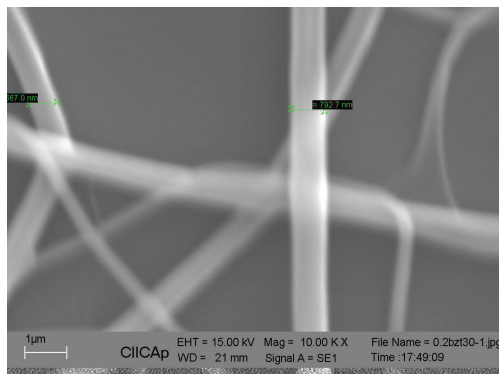

(c) $667-792 \mathrm{~nm}$

FIGURE 5: SEM micrographs of Ny-BTAH fibers with different inhibitor concentrations at $0.2 \mathrm{~mL} / \mathrm{h}$ : (a) Ny-BTAH 10\%, (b) Ny-BTAH 20\%, and (c) Ny-BTAH 30\%.

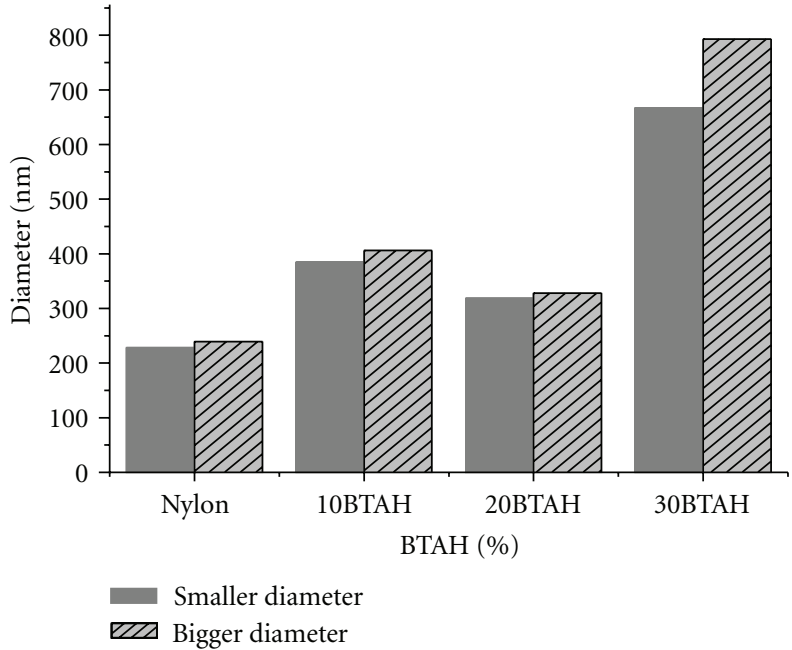

(a)

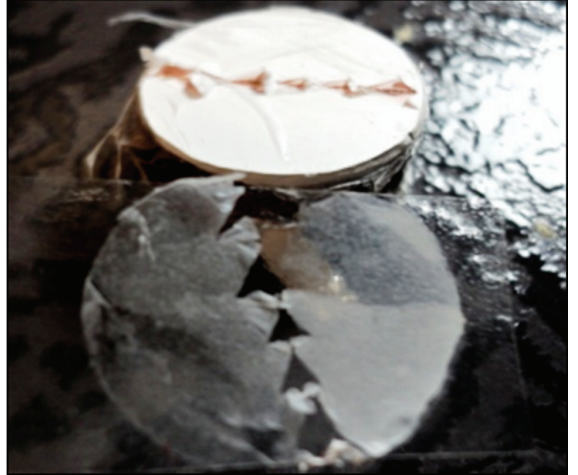

(b)

Figure 6: (a) Fiber diameter range as a function of BTAH concentration, and (b) adhesion test for Ny-BTAH 20\% copper sample.

As a preliminary step towards determining the optimal inhibitor concentration condition, electrochemical impedance and noise measurements were performed in metallic copper samples coated with electrospun nylon BTAH inhibitor. Another set of samples were also painted over with BTAH-alkyd varnish. For comparison, bare copper was also tested to obtain the blank conditions. All the samples were immersed in ammonium sulfate-sodium chloride solution for two hours prior testing. Table 1 presents the average (duplicate) electrochemical results obtained showing the barrier-inhibitor effect of the coatings. The best inhibitor concentration (higher values) was for the $20 \% \mathrm{BTAH}$, with total impedance modulus and noise resistance in the order of $4 E 6$ and $2 E 7 \mathrm{ohm}-\mathrm{cm}^{2}$, respectively. For comparison, bare copper presents a total impedance modulus and noise resistance of $1.50 E 4 \mathrm{ohms}-\mathrm{cm}^{2}$ and $1.60 E 4 \mathrm{ohms}-\mathrm{cm}^{2}$, respectively. The presence of Ny-BTAH without/with varnish increased at least one order of magnitude of the impedance values, as compared to bare $\mathrm{Cu}$ samples.

Figure 7 presents the free corrosion potential as a function of time of immersion, comparing the bare copper, nylon and varnish "only" samples (blanks), and the varnish-nylon BTAH 20\% coated sample. The bare copper sample shows an ennoblement in the potential behavior, reaching a steady state potential $(-210 \mathrm{mV})$ after $200 \mathrm{~h}$ of immersion till the end of the experiment at $912 \mathrm{~h}$, due to the formation of corrosion products

The varnish-Ny-BTAH 20\% copper coated sample presents an activating potential behavior as a function of time of immersion, reaching a steady state value, similar to the bare copper sample, at about $550 \mathrm{~h}$. Nevertheless, the sample starts at a more noble potential $(-60 \mathrm{mV})$. Up to $500 \mathrm{~h}$ of immersion the inhibitor sample presents more noble potential, compared to bare copper metal and blank samples $[18,19]$. This behavior could be ascribed to the difficulty of aggressive anions reaching the metal surface due to limitations in the diffusion path promoted by the nylon fibers and the inhibitor action [14].

It is worth noticing that the coated surface was scratched using a cutter simulating an in-service coating damage and stimulate corrosion. The scratching was done at $504 \mathrm{~h}$ of immersion, and a change in the noble direction was registered, returning back to the steady state active potential $(-210 \mathrm{mV})$. The potential change suggests that corrosion 
TABLE 1: Electrochemical impedance modulus and noise resistance as a function of BTAH concentration for electrospun nylon alkyd varnish coating.

\begin{tabular}{|c|c|c|c|c|c|c|c|}
\hline ВТАН (\%) & Bare $\mathrm{Cu}$ & Ny-BTA & $10 \%$ & Ny-BTA & $20 \%$ & Ny-BTA & $30 \%$ \\
\hline Measure & - & Without varnish & With varnish & Without varnish & With varnish & Without varnish & With varnish \\
\hline$Z_{T}$ & $1.5 E 4$ & $1.06 E 5$ & $1.42 E 6$ & $5.09 E 6$ & $9.96 E 6$ & $9.26 E 5$ & $2.10 E 6$ \\
\hline$R_{N}$ & $1.6 E 4$ & $1.09 E 5$ & $1.3 E 5$ & $2.24 E 7$ & $4.54 E 6$ & $6.50 E 5$ & $7.64 E 5$ \\
\hline
\end{tabular}

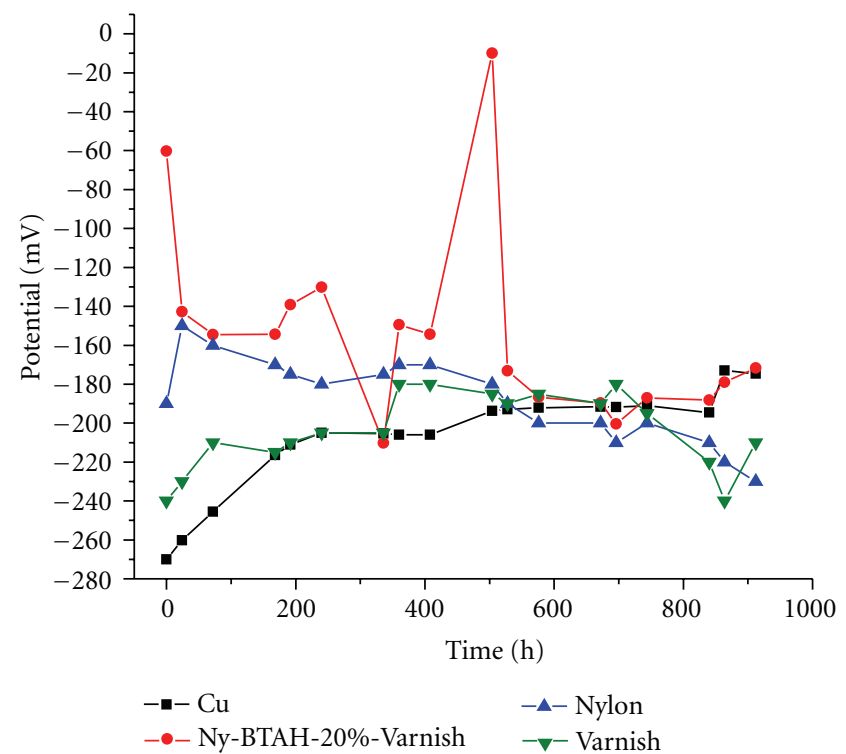

FIGURE 7: Free corrosion potential as a function of time of immersion.

and oxide film formation is taking place over copper exposed by the damaged area and promoted by the action of the benzotriazole inhibitor, which is shown as an increase in potential.

Figure 8(a) presents some of the Nyquist diagrams for the coating sample, obtained for different periods of immersion in the solution. Also the proposed equivalent circuit for the simulation of impedance data is presented to obtain the electrochemical parameters. The diagrams consist of a high frequency semicircle, followed by another intermediate frequency semicircle and a low frequency straight line or a tail or curly section leaning towards the real axis, due to the presence of the inhibitor. It is possible to observe the effect of immersion time in the graphs, and from the experimental values adjusted and obtained from the simulation using the equivalent electric circuit proposed (see Table 2 ). The presence of the BTAH inhibitor affects the electrochemical properties of the system, evidenced by the changes observed in the impedance diagrams [17].

To follow up the deterioration of metal coatings, it is common to use electrochemical impedance and the application of electrical equivalent models. Table 2 presents the simulated values obtained, using the equivalent circuit proposed. For comparison, the bare copper values for steady state conditions ( $336 \mathrm{~h}$ of immersion) are also presented. The solution resistance obtained for bare copper was 35 ohms$\mathrm{cm}^{2}$. Nevertheless, for the coated sample the solution resistance values were in the order of thousands of ohm$\mathrm{cm}^{2}$. A proposed explanation for this observation is the coupling of the solution resistance value to the high coating resistance value. This is corroborated with the decrease in the solution resistance values obtained, when the polymer coated sample was artificially damaged, diminishing to values in the order of $380 \mathrm{ohms}-\mathrm{cm}^{2}$, showing a recovering tendency to the higher values with time.

Coating impedance parameters $R_{1}$ and $Q_{1}$ provide information regarding coating dielectric properties evolution. $R_{1}$ exhibits certain proportionality correlation with metal corrosion rate under damaged coating conditions, presenting a decrease in their values as a function of time of immersion, while the coating capacitance values $\left(Q_{1}\right)$ tend to increase $[17,20,21]$. Under accelerated degradation conditions, such as in artificially damaged coatings (as in our case), the coating resistance increases due to porosity blockage or obstruction of the damaged area by the corrosion products, as well as the corrosion inhibitor compound stored in the electrospun coating $[22,23]$.

Coating capacitance $Q_{1}$ depends on the water quantity incorporated in the coating matrix as it is mentioned, and hence it was proposed as a method of interface metal coating deterioration monitoring [20]. $Q_{1}$ trend to increase as a function of exposure to the corrosion medium has been interpreted as a consequence of corrosion; therefore their values can be influenced by this process [21].

$R_{2}$ represents the charge transfer resistance associated to the corrosion process. Large values were registered along the period of immersion, diminishing after scratching the coating surface after $504 \mathrm{~h}$ of immersion, promoting corrosion of the metal and low $R_{2}$ value. Afterwards the charge transfer resistance increased again suggesting the formation of very protective film due to the BTAH inhibitor "smart" action.

The double layer capacitance $\left(Q_{2}\right)$ and charge transfer resistance $\left(R_{2}\right)$ parameters change can be observed at different periods of time, for many metal-coating systems. This is due to the corrosion process being influenced by the film resistance and capacitance of the coating system. In this case, however, the charge transfer resistance tends to increase and only decreased when the film coating was artificially damaged, increasing again afterwards. This behavior observed suggests a kinetics decrease probably because of the combined effect of the coating and the formation of a protective oxide over the metal surface, by the inhibitor action. In a similar way, the double layer capacitance also increases along the time of immersion and the $n_{1}$ and $n_{2}$ values (around 0.5) reflect far from ideal capacitive behavior. Finally the curl or tail obtained at lower frequencies shows very high $\mathrm{R} 3$ resistance values. This also reflects a capacitive 


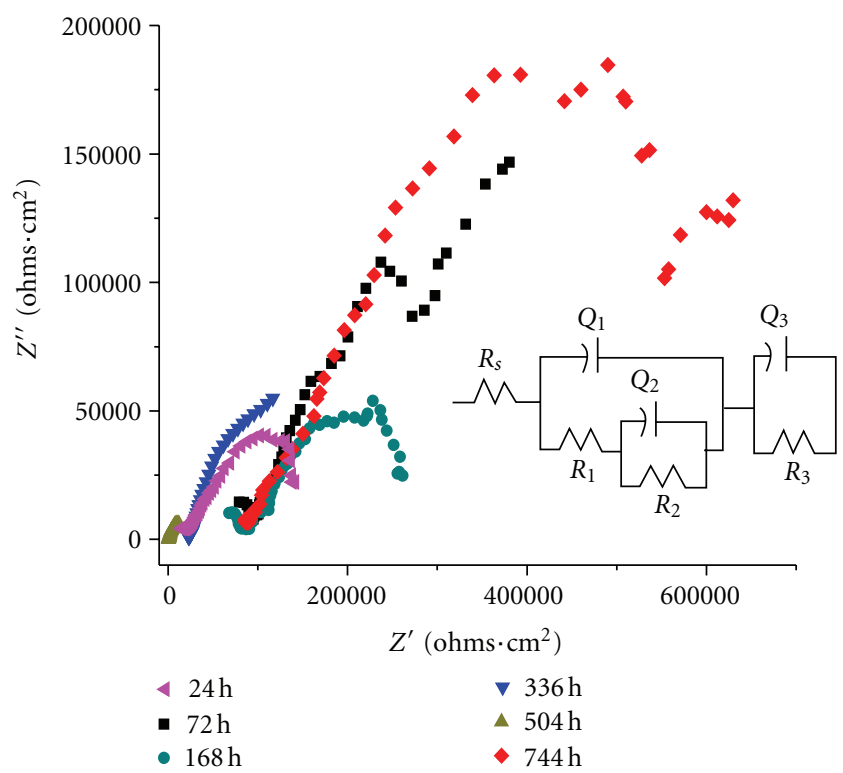

(a)

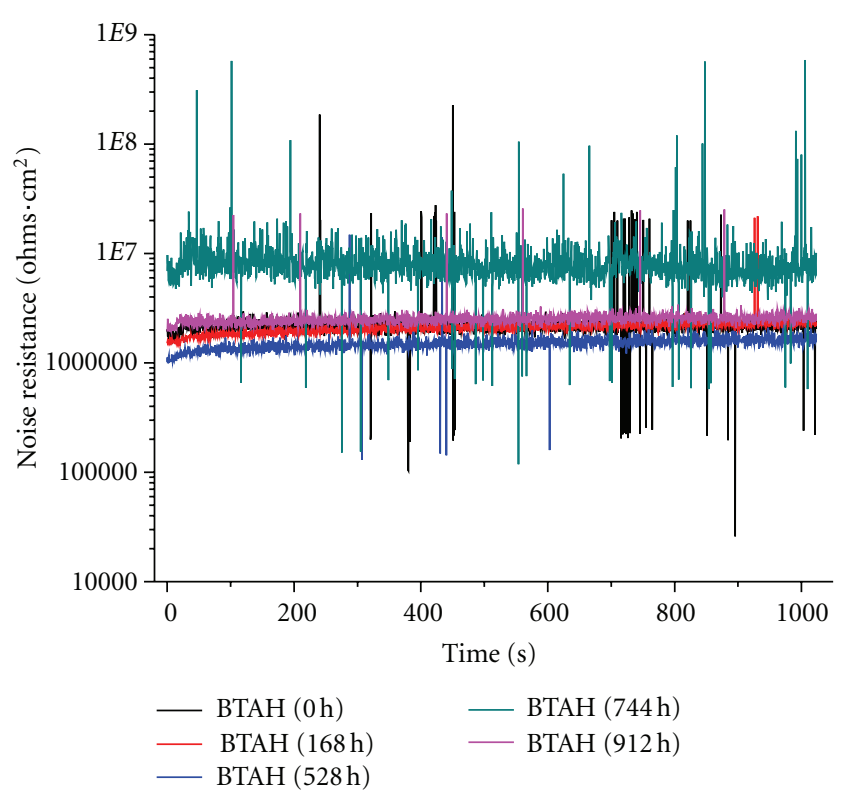

(b)

Figure 8: (a) Nyquist diagrams as a function of time of immersion and equivalent electric circuit and (b) electrochemical noise resistancetime series; for varnish-Ny-BTAH $20 \%$ sample.

TABLE 2: Values obtained from the simulation of electrochemical impedance for polymer coating varnish-Ny-BTAH $20 \%$ sample as a function of immersion.

\begin{tabular}{|c|c|c|c|c|c|c|c|c|c|c|}
\hline $\begin{array}{l}\text { Time } \\
\mathrm{h}\end{array}$ & $\begin{array}{c}R_{\mathrm{sol}} \\
\Omega * \mathrm{~cm}^{2}\end{array}$ & $\begin{array}{c}R_{1} \\
\Omega * \mathrm{~cm}^{2}\end{array}$ & $\begin{array}{c}Q_{1} \\
\mathrm{~F} * \mathrm{~cm}^{-2}\end{array}$ & $n_{1}$ & $\begin{array}{c}R_{2} \\
\Omega * \mathrm{~cm}^{2}\end{array}$ & $\begin{array}{c}Q_{2} \\
\mathrm{~F} * \mathrm{~cm}^{-2}\end{array}$ & $n_{2}$ & $\begin{array}{c}R_{3} \\
\Omega * \mathrm{~cm}^{2}\end{array}$ & $\begin{array}{c}Q_{3} \\
\mathrm{~F} * \mathrm{~cm}^{-2}\end{array}$ & $n_{3}$ \\
\hline 24 & 46628 & 52525 & $3.66 E-7$ & 0.42 & 185340 & $4.86 E-6$ & 0.53 & - & - & 一 \\
\hline 48 & 50774 & 34205 & $8.92 E-8$ & 0.57 & 439640 & $6.62 E-6$ & 0.39 & $1 E 10$ & $1.19 E-3$ & 0.50 \\
\hline 72 & 46846 & 28932 & $2.25 E-8$ & 0.67 & 862000 & $1.30 E-5$ & 0.31 & $1 E 10$ & $4.55 E-3$ & 0.45 \\
\hline 168 & 81528 & 22171 & $8.49 E-7$ & 0.51 & 329160 & $7.92 E-6$ & 0.39 & $1 E 10$ & $5.57 E-3$ & 0.56 \\
\hline 336 & 71528 & 16380 & $3.04 E-8$ & 0.52 & 869490 & $2.16 E-6$ & 0.48 & $1 E 10$ & $3.01 E-3$ & 0.80 \\
\hline 504 & 380 & 7577 & $1.42 E-6$ & 0.59 & 9337 & $1.56 E-4$ & 0.76 & - & - & - \\
\hline 744 & 3516 & 11000 & $2.17 E-5$ & 0.84 & 702700 & $3.32 E-5$ & 0.40 & - & - & - \\
\hline 912 & 22629 & 211170 & $4.63 E-7$ & 0.51 & 195000 & $1.94 E-7$ & 0.36 & $1 E 10$ & $4.61 E-5$ & 0.38 \\
\hline Cu 336 [17] & 35.18 & 944.5 & $1.41 E-6$ & 0.72 & 1592 & $2.56 E-6$ & 0.56 & - & - & - \\
\hline
\end{tabular}

behavior with $Q_{3}$ values obtained, increasing as a function of time of immersion [17]. This is probably related to the diffusion and adsorption of the inhibitor, reacting with the copper ions promoted by oxidation and the protective complex copper BTAH film formation. The mass transport controls the reaction kinetics, and the depressed semicircles experimentally obtained are related to the heterogeneities of the surface and distorted distribution of the electric field $[20,21]$.

The impedance response from the coating exposed to the corrosive media produces changes in the high frequency impedance spectra due to the formation of a polymer-metal interface from the solution entering through the polymer film (varnish) pores and the electrospun nylon interstices. The incorporation of solution promotes film capacitance $Q_{1}$ and resistance $R_{1}$ changes, forming a depressed semicircle, by the action of the time constant. As time of immersion goes on, the loss of dielectric properties increases by the presence of water and ions. This in turn is reflected in the second semicircle at mid frequencies, once the coating dielectric properties decreased, changing the charge transfer resistance. Eventually, the influence of the diffusion process may appear at low frequencies $\left(R_{3}, Q_{3}\right)$, indicating the presence of species mass transport through the metal-polymer interface controlling the process $[17,20,22]$.

When corrosion occurs in coated metals, the impedance response presents semicircles with individual time constant (RC). Capacitive behavior is observed in multilayered or thick coatings, where pores and imperfections extend and grow until they reach the metallic substrate. Coating capability to protect the metal is limited by the capacity to absorb water and aggressive ions, which deteriorates 
their dielectric properties. Nevertheless, the efficiency in its protecting properties can be improved considerably by involving additives with corrosion inhibition properties. This was observed with the use of BTAH inhibitor stored in the nylon fibers acting as nanocontainers and increasing the charge transfer resistance by its action (see Table 2).

Coating deterioration is a function of time of immersion, increasing considerably with the presence of aggressive ions, as shown by metallic-coating impedance measurements [1623]. At high inhibitor concentrations (as in this case), the low frequency tail suggests a blocking effect due to capacitive behavior depending on inhibitor concentration. Benzotriazole, as copper corrosion inhibitor for chloride media, promotes layers of polymer-oxide film formation with protective or passive properties $[17,20,21,23]$. This explains the increase in the charge transfer resistance as a function of time, up to $500 \mathrm{~h}$ of immersion. After artificially damaging the polymeric coating, a decrease in the $Q_{2}$ capacitance was observed increasing again afterwards. Also, the charge transfer diminished and increased again, suggesting the oxidation and formation of a protective film, promoted by the inhibitor release and subsequent action [24].

The high frequency capacitance reflects the capacitive behavior due to the dielectric properties of the protective film promoted by the BTAH inhibitor, being the film formed completely or partially by a polymeric oxide compound $[20,21]$. The second time constant at mid frequencies is related to the double layer capacitance coupled to the charge transfer resistance of the pores bottom. The low frequency time constant reflects the mass transport process through the insulating part of the BTAH film and the corrosive solution. This is evidenced by the film capacitive behavior at low frequencies. In this case, the charge transfer resistance cannot be accurately determined, being up to $1 E 10 \mathrm{ohm}-\mathrm{cm}^{2}$ range [17]. Therefore, at high benzotriazole concentrations, the total impedance (and noise resistance) is extremely large due to the low frequency capacitance region, indicative of such a high resistance, as observed in [15, 17, 20, 21, 23-25].

Figure 8(b) presents the electrochemical noise resistancetime series where the changes are evident in the average values during different times of immersion as well as some variable amplitude transients accompanying the signals and associated to electrochemical reaction localized effects. Noise resistance behavior shows similar trend as electrochemical impedance values. This is more evident if impedance and noise resistance are plotted as a function of time where similar behavior for both parameters is shown (Figure 9).

Figure 9(a) presents the averaged total electrochemical impedance modulus observed for bare copper, nylon and varnish "only" (blanks) samples, as well as for the copper electrospun varnish-Ny-BTAH $20 \%$ sample as a function of immersion experiment. The impedance modulus for the samples reaches a steady state value around $300 \mathrm{~h}$ of immersion. Higher impedance values (more than 3 orders of magnitude) were observed up to $400 \mathrm{~h}$, for the varnish-NyBTAH 20\% coated sample, as compared to the bare copper sample, and one order of magnitude with the other blank samples. Bear in mind the scratch made after 500 hours, where the impedance drops markedly for the coated sample, increasing again afterwards in the range of $1 E 5 \mathrm{ohms}-\mathrm{cm}^{2}$.

Similarly, Figure 9(b) presents the average noise resistance values as a function of immersion, where a drop in the average values was observed as before. Also, after scratching the surface, the "intelligent" action of the inhibitor system is evident, when after dropping the noise resistance value associated to the corrosion process rose again after oxide protective film formation and healing of the damaged area. Coated varnish-Ny-BTAH $20 \%$ sample impedance and noise resistance values remained above the bare copper and nylon and varnish only sample values throughout the experiment at around $5 E 4 \mathrm{ohms}-\mathrm{cm}^{2}[15,16,18]$. Besides, noise resistance and impedance values may be under- or overestimated, since the calculation is made considering the nominal surface area of the electrode, and after the scratch was performed, a real effective area is much smaller. In general it can be said that the total impedance modulus and the noise resistance values for the inhibitor containing samples remained higher because of the inhibitor action, until the end of the experiment

Figure 10 shows a SEM micrograph in the artificially damaged coating area. The elemental analysis performed to the sample presents corrosion products with elements associated to the electrolyte such as sodium, chloride, and sulfate. Elements revealing the presence of the polymer and inhibitor like carbon, oxygen, and nitrogen were also present. Also copper as metallic substrate and iron associated to the cutter used to cause the artificial damage over the polymer coating is also observed. All these suggest the probable formation of a layer of a polymeric oxide compound from the action of BTAH inhibitor, as reported [20,21].

Interface relaxation processes of polymers at solid surfaces is of practical importance, due to loss or dielectric relaxation and conduction processes. Anticorrosion coating protective properties over the metallic substrate are attributed to the barrier effect as the main electrochemical mechanism for the film formation process [22]. Organic coatings usually present a high ionic conductivity resistance, since they act as barriers restricting the species diffusion to and from the metallic surface. Protective properties are determined by water absorption rate, oxygen, and ion diffusion through the insulating layer, promoted by the osmotic pressure in coating capillarity pores [22]. The presence of the electrospun nylon-BTAH network not only contributes to the barrier effect as such but also provides a tortuous path for aggressive ions diffusion to occur. The action of the inhibitor is to promote oxidation (low impedance) and repassivation (high impedance) effects over the defects or damaged areas forming the polymeric oxide coating.

Based on the work by Kosec et al. [17] and the results obtained in this work, the following mechanism for copperbenzotriazole inhibitor film formation in chloride solution is proposed:

$$
\begin{gathered}
4 \mathrm{Cu}+8 \mathrm{Cl}^{-}+\mathrm{O}_{2}+2 \mathrm{H}_{2} \mathrm{O} \Longrightarrow 4 \mathrm{CuCl}_{2}+4 \mathrm{OH}^{-} \\
\mathrm{CuCl}_{2}+\mathrm{nBTAH} \Longrightarrow[-\mathrm{CuBTA}-] \mathrm{n}+\mathrm{nH}^{+}+2 \mathrm{nCl}^{-}
\end{gathered}
$$




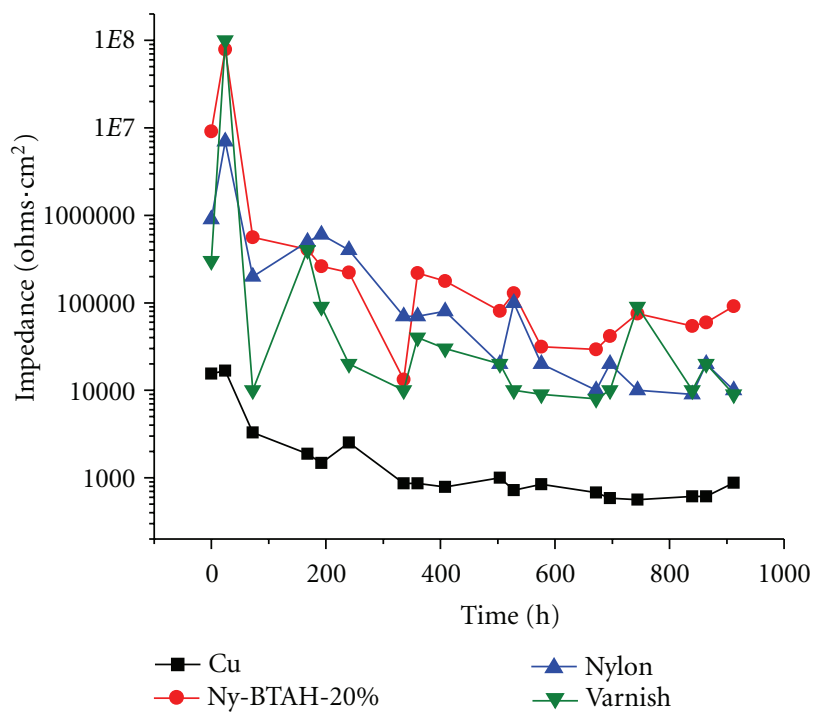

(a)

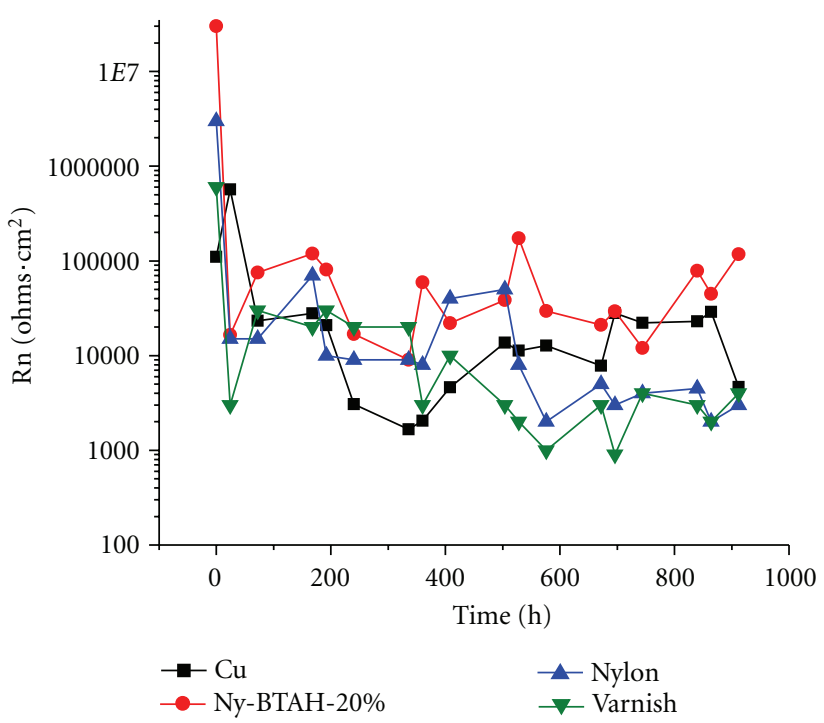

(b)

Figure 9: (a) Impedance and (b) noise resistance as a function of time of immersion; for bare Cu, nylon, varnish "only," and varnish-NyBTAH $20 \%$ coated copper.
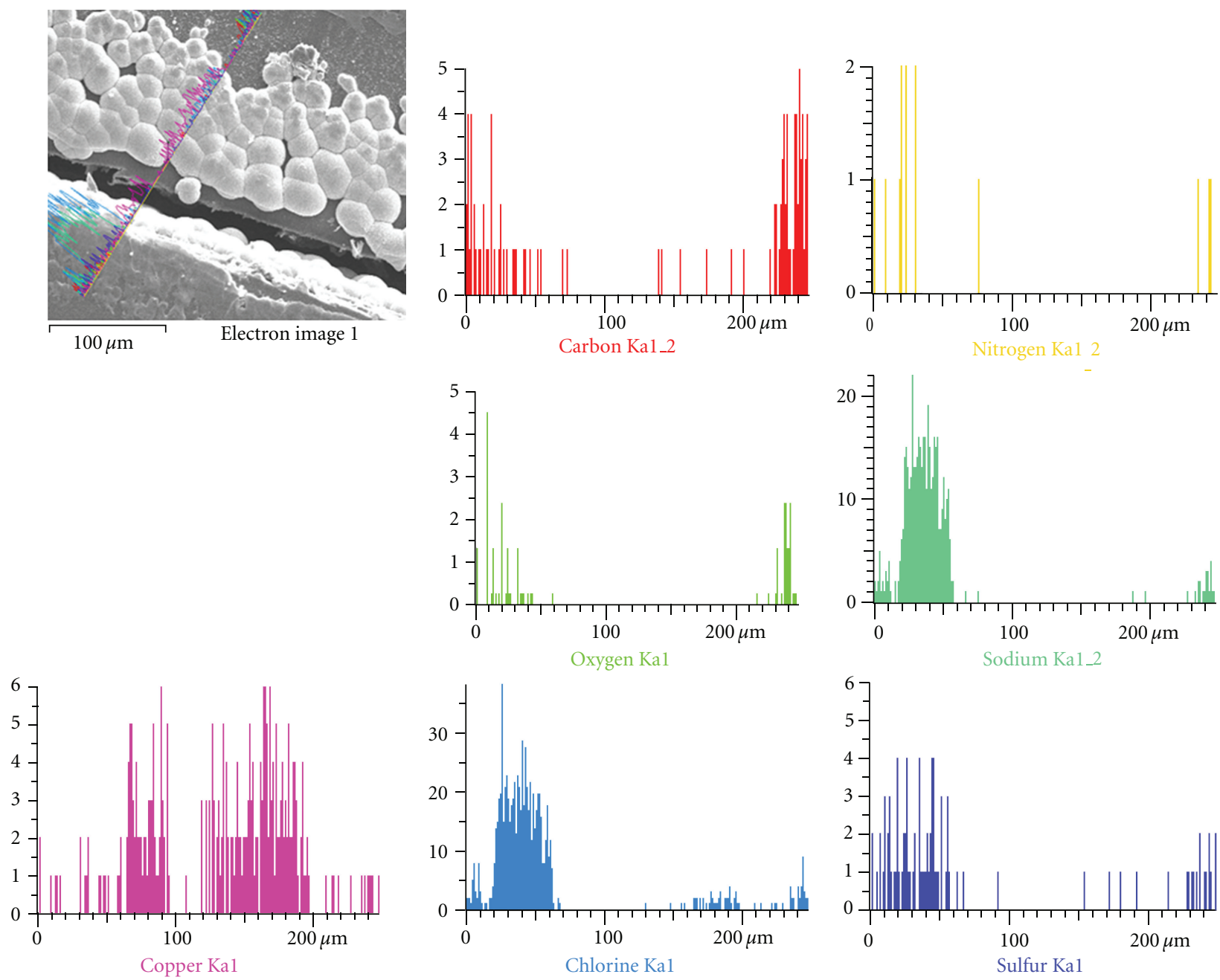

FIGURE 10: SEM micrograph and elemental analysis in the coating artificially damaged area. 


\section{Conclusions}

This work presents the electrochemical evaluation of electrospun nylon-BTAH 20\% by weight and alkyd varnish. Physical characterization was determined presenting a homogeneous distribution, an ordered preferential orientation, and thinner nylon-BTAH 20\% fibers. Its electrochemical corrosion behavior shows good performance under immersion conditions. The electrochemical impedance and noise measurements suggest a large barrier resistance and a highly capacitive behavior due to the formation of an oxide polymeric protective film formed over the copper surface.

\section{Acknowledgment}

The authors wish to thank the contribution of Dr. Griselda Zambrano for the drawings of this paper.

\section{References}

[1] D. H. Reneker and I. Chun, "Nanometre diameter fibres of polymer, produced by electrospinning," Nanotechnology, vol. 7, no. 3, pp. 216-223, 1996.

[2] A. S. Khanna, M. K. Totlani, and S. K. Singh, Corrosion and Its Control, Elsevier, Amsterdam, The Netherlands, 1998.

[3] A. I. Altsybeeva and S. Z. Levin, Metal Corrosion Inhibitors, Khimiya, Leningrad, Russia, 1968.

[4] R. Yukhnevich, V. Bogdanovich, E. Valashkovsky, and A. Vidukhovsky, Technika Przeciwkorozyina, Wydawnictwa Szkolne i Pedagogiczne, Warszawa, Poland, 1976.

[5] A. L. Yarin, S. Koombhongse, and D. H. Reneker, "Taylor cone and jetting from liquid droplets in electrospinning of nanofibers," Journal of Applied Physics, vol. 90, no. 9, pp. 4836-4846, 2001.

[6] Y. M. Shin, M. M. Hohman, M. P. Brenner, and G. C. Rutledge, "Experimental characterization of electrospinning: the electrically forced jet and instabilities," Polymer, vol. 42, no. 25, pp. 9955-9967, 2001.

[7] J. M. deitzel, J. D. Kleinmeyer, J. K. Hirvonen, and N. C. Beck Tan, "Controlled deposition of electrospun poly(ethylene oxide) fibers," Polymer, vol. 42, no. 19, pp. 8163-8170, 2001.

[8] S. Koombhongse, W. Liu, and D. H. Reneker, "Flat polymer ribbons and other shapes by electrospinning," Journal of Polymer Science B, vol. 39, no. 21, pp. 2598-2606, 2001.

[9] A. G. Rinzler, J. H. Hafner, P. Nikolaev et al., "Unraveling nanotubes: field emission from an atomic wire," Science, vol. 269, no. 5230, pp. 1550-1553, 1995.

[10] L. S. Pinchuk, V. A. Goldade, A. V. Makarevich, and V. N. Kestelman, Melt Blowing: Equipment, Technology and Polymer Fibrous Materials, Springer, New York, NY, USA, 2002.

[11] A. S. Khanna, M. K. Totlani, and S. K. Singh, Corrosion and Its Control, vol. 2, Elsevier, Amsterdam, The Netherlands, 1998.

[12] C. Menchaca, S. Hernández, A. Tejeda, E. Sarmiento, J. Uruchurtu, and M. A. Sánchez, "Adsorption of $\mathrm{Fe}\left(\mathrm{NO}_{3}\right)_{3}$ onto activated nylon 6,6 as a container and the possible smart corrosion inhibitor containing system," Adsorption Science and Technology, vol. 29, no. 5, 11 pages, 2011.

[13] E. Sarmiento, J. Uruchurtu, J. G. Gonzalez-Rodriguez, C. Menchaca, and O. Sarmiento, "Electrochemical noise analysis of type $316 \mathrm{~L}$ stainless steel in a $\mathrm{LiBr}+$ ethylene glycol $+\mathrm{H}_{2} \mathrm{O}$ solution," Corrosion, vol. 67, no. 10, Article ID 105004, 2011.
[14] L. Pawlowski, The Science and Engineering of Thermal Spray Coatings, John Wiley \& Sons, Chichester, UK, 2008.

[15] A. Soto-Quintero, J. U. Chavarín, R. C. Silva, D. Bahena, and C. Menchaca, "Electrospinning smart polymeric inhibitor nanocontainer system for copper corrosion," ECS Transactions, vol. 36, no. 1, pp. 119-127, 2011.

[16] R. Cottis and S. Turgoose, Electrochemical Impedance and Noise, NACE Internacional, Houston, Tex, USA, 1999.

[17] T. Kosec, D. K. Merl, and I. Milošev, "Impedance and XPS study of benzotriazole films formed on copper, copper-zinc alloys and zinc in chloride solution," Corrosion Science, vol. 50, no. 7, pp. 1987-1997, 2008.

[18] J. Botana and M. Marcos, Ruido Electroquímico, Métodos de Análisisp, SEPTEM, Oviedo, España, 2006.

[19] M. A. González-Núñez and J. Uruchurtu-Chavarin, "Fractal analysis of electrochemical noise signals of three organic coating samples under corrosion conditions," Journal of Corrosion Science and Engineering, vol. 6, p. C117, 2003.

[20] M. Finzgar and I. Milosev, "Inhibition of copper corrosion by 1,2,3-benzotriazole: a review," Corrosion Science, vol. 52, no. 9, pp. 2737-2749, 2010.

[21] D. Bahena, I. Rosales, O. Sarmiento, R. Guardian, C. Menchaca, and J. Uruchurtu, "Electrochemical noise chaotic analysis of NiCoAg alloy in hank solution," International Journal of Corrosion, vol. 2011, Article ID 491564, 11 pages, 2011.

[22] J. Uruchurtu and J. L. Ramírez, Método Experimental en la Corrosion: Impedancia Electroquímica, Editorial Academica Española, Berlin, Germany, 2011.

[23] F. M. Geenen and J. H. W. de Wit, "An impedance spectroscopy study of the degradation mechanism for a model epoxy coating on mild steel," Progress in Organic Coatings, vol. 18, no. 3, pp. 299-312, 1990.

[24] J. Uruchurtu, J. L. Ramírez, J. M. Malo, V. Juarez-Rivera, and C. A. Quintero-Portillo, "Electrochemical method to evaluate rapid degradation of multi-layer coatings on high strength galvanized," ECS Transactions, vol. 29, no. 1, pp. 13-21, 2010.

[25] C. Avila-Gonzalez, R. Cruz Silva, C. Menchaca, S. SepúlvedaGuzman, and J. Uruchurtu, "Use of silica tubes as nanocontainers for corrosion inhibitor storage," Journal of Nanotechnology, vol. 2011, Article ID 461313, 9 pages, 2011. 

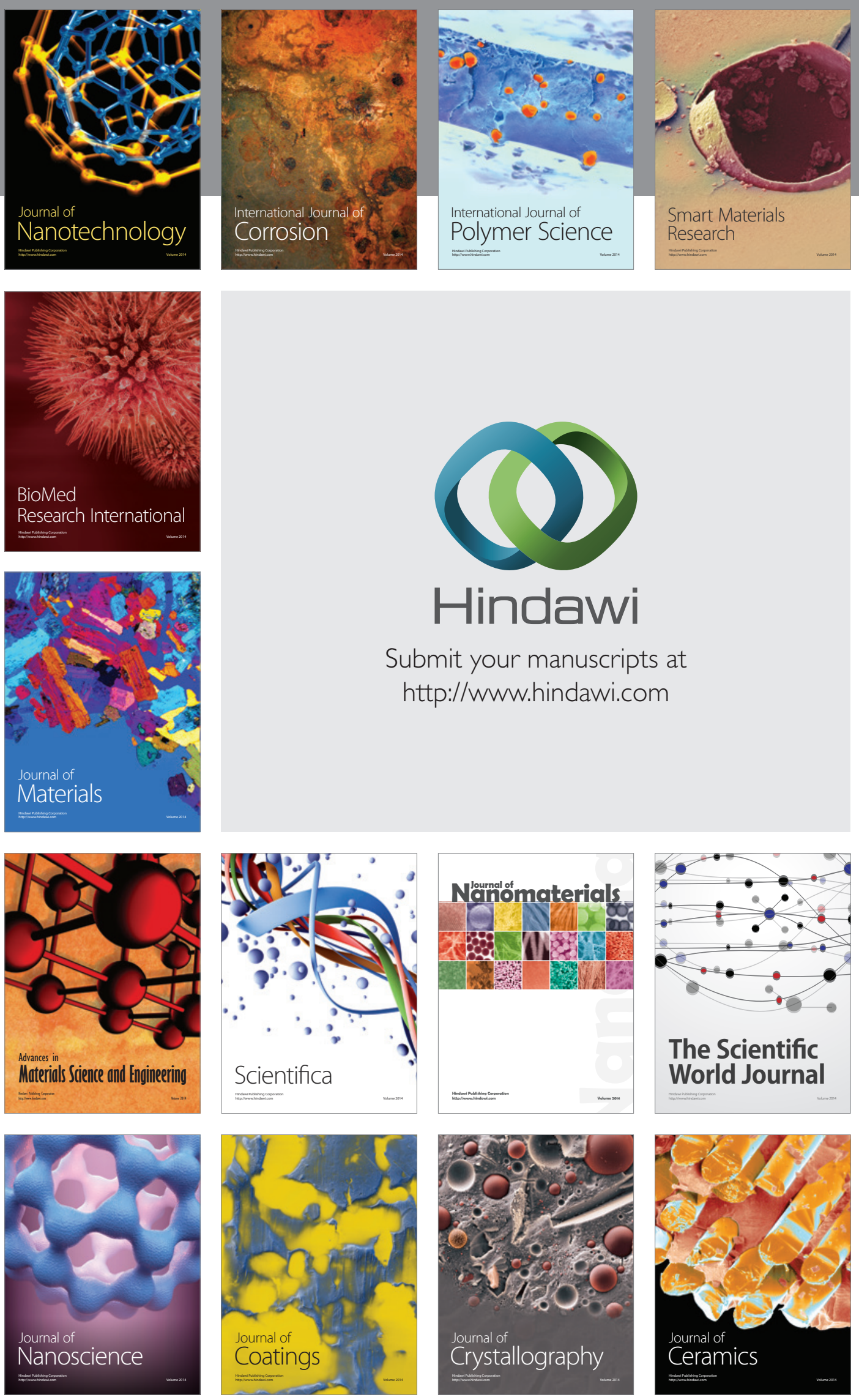

The Scientific World Journal

Submit your manuscripts at

http://www.hindawi.com

\section{World Journal}

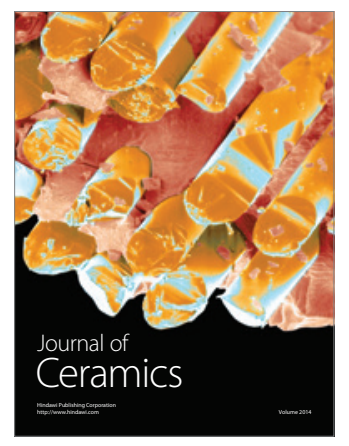

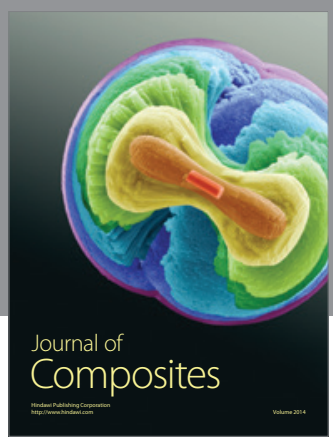
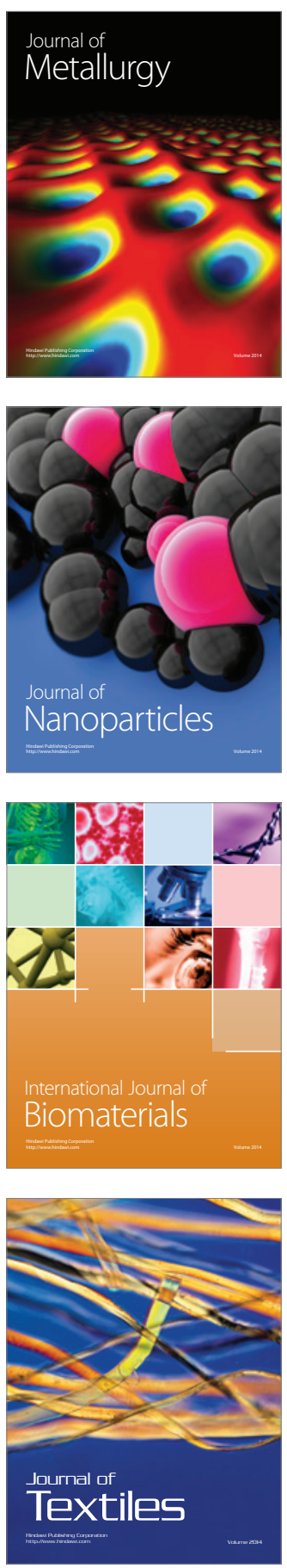